\title{
A FAMÍLIA CONTEMPORÂNEA E SEUS VALORES: UM OLHAR PARA A COMPREENSÃO PARENTAL
}

THE CONTEMPORARY FAMILY AND THEIR VALUES: STARING AT PARENTAL UNDERSTANDING

LA FAMILIA CONTEMPORÁNEA Y SUS VALORES: UNA MIRADA A LA COMPRENSIÓN PARENTAL

\author{
Mariana Filippini Cacciacarro* \\ Rosa Maria Stefanini de Macedo*
}

\begin{abstract}
RESUMO
Baseada no referencial sistêmico novo paradigmático proposto por Vasconcellos (2003), esta pesquisa teve como objetivo compreender a perspectiva parental quanto à transmissão de valores aos filhos diante do processo de educá-los. Trata-se de um estudo realizado com base em entrevistas com quatro casais casados, com ao menos um filho de idade entre 4 e 6 anos. As entrevistas ocorreram separadamente, com o intuito de captar possíveis diferenças no relacionamento dos pais com as crianças. A análise qualitativa e interpretativa utilizada visou a compreender os significados atribuídos pelos pais aos valores que orientam e sustentam a tarefa educativa, os quais estão intimamente relacionados à subjetividade e, por conta disso, há grande dificuldade dos pais em nomear, com clareza, aqueles que alicerçam suas atitudes e comportamentos. Os participantes afirmam que amor, responsabilidade, compreensão, criatividade e ética permeiam essa tarefa, realçando que o mais difícil é assumir atitudes não autoritárias e pautadas no diálogo.
\end{abstract}

Palavras-chave: Valores. Família. Sistemas. Parentalidade. Diálogo. Educação.

\footnotetext{
ABSTRACT

Based on the new systemic paradigmatic framework proposed by Vasconcellos (2003), this study aimed to understand the parental perspective concerning the transmission of values to children within the process of educating them. This is a case study based on interviews with four married couples with at least one child aging between four to six years. The interviews took place

Texto recebido em 25 de fevereiro de 2015 e aprovado para publicação em 10 de maio de 2016.

* Mestranda em Psicologia Clínica pela Pontifícia Universidade Católica de São Paulo (PUC São Paulo), especialista em Terapia de Família e Casal, psicóloga. E-mail: m.fcacciacarro@gmail.com.

** Doutora em Psicologia Clínica pela PUC São Paulo, graduada em Pedagogia pela Faculdade de Filosofia, Ciências e Letras de São Bento, professora emérita da PUC São Paulo, coordenadora do Núcleo de Família e Comunidade do Programa de Pós-Graduação em Psicologia Clínica da PUC São Paulo e professora titular na mesma universidade, coordenadora do Curso de Especialização em Terapia Familiar e de Casal, COGEAE PUC-SP. Tem experiência na área de Psicologia, com ênfase em Psicologia do Desenvolvimento Humano e Psicologia da Família, atuando principalmente nos temas família, estrutura e dinâmica; família e instituiçōes; terapia sistêmica familiar e de casal; sexualidade e gênero; projetos sociais com foco na família. E-mail: romacedo@pucsp.br.
} 
separately in order to capture possible differences in the relationship with the children. The qualitative and interpretative analysis used aimed to understand the meanings attributed by parents to the values that guide and support the educational task which are closely related to subjectivity and because of that it is very difficult for parents to name clearly those values that underpin their attitudes and behaviors. Participants say love, responsibility, understanding, creativity and ethics pervade this task, stressing that the most difficult is to take dialogue-based non-authoritarian attitudes.

Keywords: Values. Family systems. Parenting. Dialogue. Education.

\section{RESUMEN}

Basado en el nuevo marco paradigmático sistémico propuesto por Vasconcellos (2003), este estudio tuvo como objetivo comprender la perspectiva parental en la transmisión de valores a los niños ante el proceso de educarlos. Este es un estudio de caso realizado a partir de entrevistas con cuatro parejas casadas con al menos un niño de cuatro a seis años. Las entrevistas se llevaron a cabo por separado con el fin de captar posibles diferencias en la relación con los niños. El análisis cualitativo e interpretativo utilizado pretendió comprender los significados atribuidos por los padres a los valores que guían y apoyan la tarea educativa. Estos valores están estrechamente relacionados con la subjetividad y, debido a eso, es muy difícil para los padres nombrar con claridad aquellos que fundamentan sus actitudes y comportamientos. Los participantes dicen que el amor, la responsabilidad, la comprensión, la creatividad y la ética impregnan esta tarea, haciendo hincapié en que lo más difícil es tomar actitudes no autoritarias basadas en el diálogo.

Palabras clave: Valores. Familia. Sistemas. Parentalidad. Diálogo. Educación.

\section{INTRODUÇÃO}

experiência clínica do atendimento a crianças e famílias nos permitiu perceber
diferenças na percepção dos pais em relação à transmissão de valores e ao
processo de educação dos filhos. Observa-se que muitos de nossos clientes
tendem a apresentar comportamentos individualistas e egocêntricos que podem
vir a dificultar o relacionamento familiar e interpessoal dos filhos no futuro.

Considerando-se a responsabilidade da família diante da formação das crianças, como matriz da identidade pessoal, é de fundamental importância considerar os valores que a permeiam e que são transmitidos aos filhos.

O paradigma no qual se baseia este trabalho prioriza a subjetividade visto que concebe a construção da realidade de acordo com a percepção do sujeito que 
observa, portanto, influenciada pelas suas experiências de vida, as quais se dão sempre na relação social, em que, por intermédio da linguagem, são construídos os significados a serem atribuídos ao mundo percebido (Grandesso, 2011).

Conforme o conceito de novo paradigma da Ciência, formulado por Vasconcellos (2003), a construção da realidade é concebida por meio de aspectos processuais, relacionais e contextuais de acordo com o pensamento sistêmico cibernético. Ao pensar sistemicamente, amplia-se o foco de observação para abarcar o maior número de características possível do fenômeno (pressuposto da complexidade), admitindo-se sua variabilidade e inconstância (pressuposto da instabilidade), e a construção social da atribuição de significados (pressuposto da intersubjetividade).

Desse ponto de vista, a família é compreendida como um todo organizado, cujas partes estão em contínua interação. Tais partes são denominadas subsistemas (parental, conjugal, fraterno, intergeracional, entre outros). Apresentam organização e funcionamento próprios, podendo ser estudados separadamente, porém cada um per se não é suficiente para explicar o sistema como um todo. Por exemplo, não se pode definir uma família apenas pelas características de um de seus membros ou de um subsistema, de filhos ou de pais.

A interação entre as partes é fundamental para caracterizar o sistema familiar, que é visto como um sistema aberto e em contínua interação com o ambiente, variando, portanto, de acordo com os aspectos socioculturais vigentes

A globalização resultante dos avanços científicos e tecnológicos na economia, na comunicação, os movimentos sociais a partir dos anos 60 do século XX, com $\mathrm{o}$ advento dos anticoncepcionais e a luta pelo reconhecimento das minorias, especialmente de gênero, produziram transformaçôes nas configurações e na dinâmica familiar contemporâneas, apresentando-se hoje novas e diversas formas de "ser família".

O modelo tradicional de família composta por pai, mãe e filhos vem se modificando com o passar dos anos em razão das mudanças decorrentes desses processos globalizantes, de tal modo que hoje se consideram famílias os mais variados arranjos: monoparental, homoafetiva masculina e feminina, a produção independente, resultante de fertilização.

$\mathrm{Na}$ convivência entre seus membros, a família vai construindo modos de se relacionar que, ao serem repetidos ao longo do tempo, acabam se transformando em padrões presentes nos comportamentos de seus membros e transmitidos através de gerações. A maneira de se comunicar, de expressar afetos, lidar com emoções, enfrentar conflitos, estabelecer fronteiras entre os subsistemas ou 
limites ao que é aceitável, estabelecer hierarquia, regras, exercer autoridade e se comportar diante delas são padrôes que caracterizam a organização, a estrutura e o funcionamento familiar (Minuchin, 1982).

Todos os comportamentos resultantes de tais padrões são sustentados por valores que os qualificam como mais ou menos éticos, de acordo com a moral social vigente em cada cultura. Nesse sentido, a família, como placenta cultural, representa o alicerce para a transmissão e cultivo de valores às gerações futuras (Macedo, 2008).

A organização e o funcionamento familiar refletem os padrões de convivência anteriormente estabelecidos entre as gerações. A família necessita organizar e reestruturar o seu funcionamento a partir das mudanças que vão ocorrendo no ciclo da vida individual e familiar, em razão do processo de desenvolvimento pessoal e das transformaçôes sociais no contexto dessa família. Alguns exemplos desses fatores de mudança são o casamento, o nascimento dos filhos, sua entrada na escola, a saída de casa, separaçôes, mortes, doenças, acidentes naturais, desemprego, entre outros.

Dessa forma, quando se fala em transmissão de valores, é necessário considerar que os padrões também podem mudar e, consequentemente, os valores podem ser revistos, devendo ser renegociados pelo casal, assim como a aquisição e experimentação de novos papéis, que, forçosamente, implicam o exercício de novas responsabilidades e tarefas (Cerveny \& Berthoud, 2010; Cunha, Guimarães \& Mourão, 2008; Minuchin, 1982).

Partindo do pressuposto que a família é um espaço privilegiado no processo de transmissão de valores, acreditamos que a complexidade e a dinâmica da vida atual, principalmente nas grandes cidades, bem como as mudanças nos papéis familiares de pai e mãe, o aumento do número de crianças cuidadas por funcionários e as atividades escolares/educativas em período integral caracterizam uma terceirização da tarefa de educar, fazendo com que as crianças cresçam inseridas em uma estrutura familiar ampliada pela participação de terceiros, que pode dificultar a satisfação de suas necessidades afetivas, emocionais e sociais (Martins Filho, 2012; Gomide, 2011; Kobarg, Sachetti \& Vieira, 2006; Cerveny \& Kublikowski, 1998).

Em 1982, Minuchin já argumentava sobre o processo de transição que a sociedade vinha enfrentando e enfatizava que a família, como parte da sociedade, também estava passando por mudanças. Por essa razão, além das dificuldades nas transições dos ciclos da vida pelos quais passa a família, sua tarefa psicossocial se tornou mais importante. Assim, reforça-se a ideia de que estudos envolvendo famílias devem incluir sua complementariedade com a sociedade, pois, tendo 
em vista os conceitos sistêmicos de circularidade e retroatividade, observa-se que não apenas a estrutura, mas também as funções familiares se modificam conforme a sociedade muda, do mesmo modo que recursivamente contribuem para a mudança da sociedade.

Diferentemente daquela família tradicional burguesa, observamos que, na atualidade, as fronteiras intra e extrafamiliares, que eram bastante rígidas, encontram-se difusas, refletindo uma maior permeabilidade entre a sociedade e a família, a qual, sendo um sistema autorregulador, tem recursos para criar ou buscar novas formas de funcionamento (Minuchin, 1982).

Muitas vezes essa ausência de fronteiras familiares bem definidas pode resultar em um maior grau de entrelaçamento entre a estrutura social e familiar, fazendo com que a sociedade assuma funções que antes eram consideradas deveres exclusivos da família (Martins Filho, 2012).

Nesse constante processo de mudança, pode-se observar que as questôes de hierarquia e dos limites envolvendo a autoridade parental se esmorecem, fomentando a insegurança nos adultos, quanto aos valores e crenças que lhes foram transmitidas, o que, muitas vezes, resulta em conflitos intergeracionais expressos no interior das famílias (Santos, 2006; Morici, 2008).

Por essa razão afirmamos que talvez um dos grandes desafios da educação seja inscrever no projeto de liberdade de cada um os valores próprios da cultura em cada tempo e lugar (Macedo, Kublikowski \& Berthoud, 2006; Santos, 2006).

Compreendemos valores como crenças que se expressam na excelência das ações e não estão apenas ligados a histórias individuais, mas inscritos nas histórias das sociedades. Os valores são relativamente determinados por culturas particulares, em razão de certos momentos históricos, variando de acordo com cada sociedade e período de sua existência. Dessa forma, não existem valores universais, e sua transmissão se inscreve em nossa história pessoal, além da bagagem genética, um capital social; portanto o patrimônio informacional é constituído pelos saberes acumulados pelas geraçôes. Cada um de nós representa uma conexão na passagem dos valores de uma geração a outra; não é uma simples repetição, pois ressignificamos e renovamos constantemente essas informaçoes, mantendo uma cota de certezas relativas sobre o que é importante transmitir (Cacciacarro, 2013; Macedo \& Kublikowski, 2009; Seixas, 2008; Cerveny \& Kublikowski, 1998).

Ao analisarmos o contexto em que estamos inseridos, é possível perceber profundas mudanças culturais nos valores, nas práticas sociais observáveis no comportamento das pessoas e nos significados atribuídos às suas ações. Características como comportamentos mais regidos pelo individualismo e pelo 
consumismo, marcados sobretudo pela busca do prazer instantâneo, a fragilidade dos vínculos por causa do imediatismo dominante nas relações tem seus reflexos nos relacionamentos que se estabelecem cotidianamente entre as pessoas, fazendo emergir problemas éticos e morais (Santos, 2011; Santos \& Macedo, 2008).

Seixas (2008) pontua que nos encontramos diante de uma fase de vertiginosas mudanças, em que há "quebra de valores preexistentes" e ausência de novos valores relacionais, estáveis, estruturados e bem aceitos. Em contrapartida, também afirma que necessitamos de tempo para vivenciar, questionar e pensar para então podermos adotar criticamente nossos valores. Contudo a rapidez das experiências do mundo atual não facilita essa explicitação clara de preceitos e comportamentos norteadores, devidamente vivenciados e valorizados, deixandonos em um desamparo quanto aos valores que embasam nossas ações.

Estamos, por conseguinte, diante de uma crise de paradigma, um momento de transição em que, cada vez mais, nos é cobrada uma compreensão do mundo como unidade complexa. Por tal concepção, deparamo-nos com a epistemologia construtivista, a qual afirma que cada um de nós é capaz de apreender aspectos dessa realidade complexa, pois os selecionamos com base em nossas próprias vivências e experiências anteriores, atribuindo significados particulares a cada situação.

Segundo Santos \& Macedo (2008), do ponto de vista da complexidade, parece ser acertado afirmar que vivemos a ética da ambivalência. Contudo uma possível solução para esse conflito associado à interposição da relação entre pais e filhos, no contexto educativo da família, vai em direção do que propõe Morin (2005). O autor considera que quanto mais complexa se torna uma sociedade, mais a ética se faz necessária, uma vez que os limites pesam sobre os indivíduos e os grandes grupos se tornam menos rígidos ou coercitivos, fazendo com que o conjunto social se beneficie de estratégias, iniciativas, invenções ou criações individuais.

Morin (2005) afirma que o excesso de complexidade pode destruir os limites, tornando flexíveis os laços sociais e, em contrapartida, a própria complexidade pode diluir-se na desordem e no caos, afetando os sistemas de valores das pessoas. Desse modo, uma sociedade de alta complexidade deveria garantir sua coesão, não somente por leis justas e instituições sólidas, mas também pela responsabilidade, solidariedade, inteligência, iniciativa e consciência dos indivíduos.

Cada vez mais, a ética e a responsabilidade pessoal se tornam indispensáveis, visto que cada família tem que agir de acordo com o seu sistema de crenças e valores, firmando-se naquilo que acredita. 
Nos últimos dez anos, houve um aumento significativo do interesse de pesquisadores em relação a temas referentes à educação, transmissão de valores e práticas educativas. Acreditamos que tal aumento se deve sobretudo às mudanças e transformações socioculturais contemporâneas, que envolvem novas maneiras de se relacionar, leis de proteção à criança e ao adolescente além da crescente preocupação parental sobre os reflexos de como criam seus filhos no futuro destes. Entretanto o corpo teórico das publicações ainda é restrito e aborda principalmente a fase da adolescência, o que leva a uma ausência de informações referentes às idades anteriores, por pesquisadores brasileiros, tanto em termos de metodologia como em relação às possibilidades de aprofundamento e continuidade na construção do conhecimento na investigação desses fenômenos. Há, portanto, uma necessidade emergente de trabalhos focados nas diferentes etapas do desenvolvimento, tanto das crianças quanto das famílias, uma vez que as relações entre pais e filhos se alteram em função da fase de desenvolvimento destes e da etapa do ciclo vital em que as famílias se encontram (Macarini, Martins, Minetto \& Vieira, 2010).

Estudar a relação entre pais e filhos em seus primeiros anos caracteriza uma forma importante de embasar intervençôes precoces e promoção de saúde, uma vez que é nessa fase que vínculos e padrões de relacionamento começam a ser estabelecidos, dando início ao processo de construção da identidade pessoal. Ademais, há uma escassez de estudos e instrumentos que avaliem as práticas parentais e seus reflexos na vida futura dos filhos.

Com base em tais considerações, propomos um estudo capaz de destacar o processo educacional familiar, suas peculiaridades, mediante a investigação profunda da perspectiva parental diante da tarefa de educar e sua complexidade.

\section{MÉTODO}

\subsection{Tipo de pesquisa}

Desenvolvemos um estudo qualitativo interpretativo por acreditarmos ser a metodologia qualitativa a mais adequada para captar a diversidade existente no âmbito familiar, que, por sua vez, contempla inúmeras possibilidades de experiências e significados (Creswell, 2009; Macedo et al., 2004).

Macedo (2008) afirma que, nas pesquisas qualitativas com famílias e casais, o foco de estudo são os processos que criam e sustentam as realidades construídas com base na intersubjetividade familiar. Desse modo, optamos por realizar separadamente entrevistas com cada casal participante, pois assim acreditamos 
ser possível compreender as tramas subjetivamente construídas diante dos relacionamentos intrafamiliares.

Para a análise dos dados obtidos nas entrevistas, recorreu-se à interpretação qualitativa, por permitir a construção de significados baseados nas respostas dadas pelos entrevistados, com o objetivo de compreender o fenômeno por nós estudado, em suas particularidades. Portanto, de acordo com os princípios da pesquisa qualitativa, os resultados buscam descrever e aprofundar a compreensão do objeto de estudo, oferecendo elementos para programar ações e intervenções mais adequadas a cada contexto específico, lembrando, contudo, que a pesquisa qualitativa não tem como objetivo a generalização, mas sim a transferibilidade para situaçôes semelhantes, como afirmam Guba e Lincoln (1994). Além disso, pode fornecer pistas para estudos quantitativos nesse âmbito, os quais, por sua vez, fornecerão novas indicações para a pesquisa qualitativa visando a aspectos específicos para orientação de intervenções adequadas a diferentes grupos.

Devemos por fim destacar que o pesquisador qualitativo não é neutro, pois, em decorrência do paradigma que norteia sua visão de mundo, a realidade não pode ser conhecida tal qual ela é, mas sim apreendida pelo observador de acordo com sua experiência, seus conhecimentos, sua cultura. Dessa forma, o observador é parte do que é percebido como real pela atribuição de significado ao que percebe, reafirmando que o conhecimento da realidade é subjetivo.

\subsection{Participantes}

Participaram desta pesquisa quarto casais casados legalmente, pais de pelo menos um filho com idade entre 4 e 6 anos. Não houve restrição quanto à religião, condição socioeconômica, nível de educação parental e número de filhos. Portanto o principal critério de inclusão adotado foi a faixa etária dos filhos do casal.

Tabela 1. Características dos casais participantes e dos filhos

\begin{tabular}{|c|c|c|c|c|c|c|}
\hline Casal & $\begin{array}{c}\text { Idade dos } \\
\text { membros do } \\
\text { casal }\end{array}$ & $\begin{array}{c}\text { Tempo de } \\
\text { casamento }\end{array}$ & Escolaridade & $\begin{array}{c}\text { Número } \\
\text { de } \\
\text { filhos }\end{array}$ & $\begin{array}{c}\text { Idade e } \\
\text { sexo dos } \\
\text { filhos }\end{array}$ & $\begin{array}{c}\text { Escola } \\
\text { dos filhos }\end{array}$ \\
\hline $\begin{array}{c}\text { Casal } \\
1\end{array}$ & $\begin{array}{c}\text { Esposa: } 33 \\
\text { Marido: } 34\end{array}$ & 10 anos & $\begin{array}{c}\text { Ambos: superior } \\
\text { completo }\end{array}$ & 2 & $\begin{array}{c}6 \text { anos } \\
\text { menina } \\
4 \text { anos } \\
\text { menino }\end{array}$ & Particular \\
\hline
\end{tabular}




\begin{tabular}{|c|c|c|c|c|c|c|}
\hline $\begin{array}{c}\text { Casal } \\
2\end{array}$ & $\begin{array}{l}\text { Esposa: } 37 \\
\text { Marido: } 41\end{array}$ & 13 anos & $\begin{array}{l}\text { Ambos: superior } \\
\text { completo }\end{array}$ & 2 & $\begin{array}{l}13 \text { anos } \\
\text { menino } \\
5 \text { anos } \\
\text { menina }\end{array}$ & Particular \\
\hline $\begin{array}{c}\text { Casal } \\
3\end{array}$ & $\begin{array}{l}\text { Esposa: } 35 \\
\text { Marido: } 36\end{array}$ & 11 anos & $\begin{array}{l}\text { Esposa: superior } \\
\text { completo } \\
\text { Marido: } \\
\text { cursando técnico }\end{array}$ & 2 & $\begin{array}{l}10 \text { anos } \\
\text { menina } \\
6 \text { anos } \\
\text { menina }\end{array}$ & Particular \\
\hline $\begin{array}{c}\text { Casal } \\
4\end{array}$ & $\begin{array}{l}\text { Esposa: } 37 \\
\text { Marido: } 37\end{array}$ & 9 anos & $\begin{array}{l}\text { Esposa: superior } \\
\quad \text { completo } \\
\text { Marido: segundo } \\
\text { grau completo }\end{array}$ & 2 & $\begin{array}{l}6 \text { anos } \\
\text { menino } \\
4 \text { anos } \\
\text { menina }\end{array}$ & Particular \\
\hline
\end{tabular}

Fonte: dados da pesquisa.

Dos quatro casais recrutados, três foram indicados por colegas terapeutas de família que sabiam da pesquisa e conheciam casais que atendiam aos critérios de inclusão. Um voluntariou-se por se interessar pelo tema pesquisado, caracterizando-se, portanto, a amostra como de conveniência.

\subsection{Instrumentos}

Como instrumento de coleta de dados, recorreu-se a uma entrevista semiestruturada, com questôes abertas, a partir de um roteiro norteador (apêndice 1), que foi gravada em um dispositivo móvel e posteriormente transcrita para fins de análise e interpretação, conforme os objetivos anteriormente propostos.

As questóes componentes do roteiro de entrevista foram formuladas a partir de conceitos e temas abordados e discutidos pela literatura revisada (Kobarg et al., 2006; Macedo, Kublikowski \& Berthoud, 2006; Santos, 2006; Cunha et al., 2008; Santos \& Macedo, 2008; Macedo \& Kublikowski, 2009; Cerveny \& Berthoud, 2010; Macarini et al., 2010; Santos, 2011), resultando na construção de cinco categorias a priori:
a) o que entendem por valores;
b) quais valores são considerados importantes pelo casal;
c) percepção dos pais diante da tarefa de educar;
d) práticas educativas utilizadas pelo casal;
e) desafios enfrentados durante o processo educacional. 


\subsection{Procedimentos: coleta de dados}

As entrevistas baseadas em temas de interesse da investigação transcorreram de forma dialogada, em que os entrevistados tiveram liberdade para discorrer espontaneamente sobre as questôes apresentados. As conversas foram realizadas em local reservado, em que não houve intercorrências relativas a ruídos e privacidade, tendo duração média de uma hora e meia. As narrativas foram posteriormente transcritas, com o propósito de análise e interpretação, conforme descrito anteriormente.

Como procedimentos éticos, seguimos a Resolução 466/12 do Conselho Nacional de Saúde, a qual regulamenta as pesquisas com seres humanos. Dessa forma, os casais receberam um termo de consentimento livre e esclarecido em duas vias que explicitava e informava os objetivos pesquisados e autorizava o encerramento da participação, caso os participantes o julgassem necessário.

Esta pesquisa está inscrita no CAAE sob protocolo 17710013.0.0000.5482, foi aprovada pelo Comitê de Ética da Universidade a qual está vinculada, sob o parecer no 499.849 .

\section{RESULTADOS}

\subsection{Análise e discussão}

A análise das entrevistas foi feita de acordo com a proposta de Macedo et al., (2004), em uma perspectiva hermenêutica: a partir de sucessivas leituras dos conteúdos transcritos, buscamos compreender, com base nas narrativas desenvolvidas pelos pais, os significados por eles atribuídos às situações apresentadas.

Os casais participantes tinham uma média de idade de 36 anos, fato que nos permitiu classificá-los como pertencentes às gerações nascidas entre os anos de 1970 e 1980, época em que o autoritarismo vigente começava a ser questionado cultural e socialmente. São fruto de uma geração com novos ideais e que representava a esperança para o País, rumo à democracia e à igualdade entre a população.

Entre suas características, destacavam-se a valorização do trabalho, liberdade de escolha, a busca da ascensão e satisfação profissional. Essa geração viveu a quebra dos padróes sociais e morais que costumavam orientar a sociedade, sendo educada com base na liberdade, na igualdade e no consumo (Lombardia, 2008). Dessa forma, observamos que os indivíduos que se desenvolveram nesse contexto tornaram-se pais preocupados com o futuro dos filhos, com algumas dificuldades 
no que tange à colocação de limites e que buscam prover os filhos de maneira a suprir tudo aquilo que consideraram falho em seu processo educacional, incluindo os aspectos materiais.

Em nosso estudo, consideramos relevante compreender qual a concepção de valor que cada casal tinha, uma vez que, ao pensarmos a construção de conhecimento na Pós-Modernidade, entenderemos que, por basear-se em um paradigma subjetivista, aceita como válidas diferentes descriçôes de um mesmo fenômeno, pelo fato de serem embasadas em vivências e experiências individuais. Portanto, ao observarmos o quadro 1, depararemos com visóes distintas sobre a primeira categoria: "O que entendem por valores".

Quadro 1. O que entendem por valores

\begin{tabular}{|c|l|}
\hline $\mathbf{1}$ & $\begin{array}{l}\text { O que buscam transmitir e ensinar aos filhos } \\
\text { dentro do convívio familiar. Acreditam que valores } \\
\text { estão relacionados à construção de uma base sólida } \\
\text { de educação. }\end{array}$ \\
\hline $\mathbf{2}$ & $\begin{array}{l}\text { O que transmitem aos filhos por meio de uma } \\
\text { relação leal, humana e próxima. }\end{array}$ \\
\hline $\mathbf{3}$ & $\begin{array}{l}\text { Aquilo que se ensina no convívio familiar, } \\
\text { permeado pelo amor e carinho. }\end{array}$ \\
\hline $\mathbf{4}$ & O que tentam passar para as crianças na família. \\
\hline
\end{tabular}

Fonte: elaborado pelos autores.

Podemos afirmar que os quatro casais entendem que os valores estão relacionados com a transmissão de conceitos feita pela família, com ligeiras modificações quanto às formas. Além disso, associam esses conceitos à construção de alicerces flexíveis capazes de instrumentalizar os filhos para o convívio em sociedade.

É válido destacar que os casais constroem suas narrativas sobre o tema baseados em sentimentos e valores que gostariam de transmitir, como é o caso da lealdade, humanidade, do amor e do carinho.

A esse respeito, retomamos a argumentação proposta por Macedo \& Kublikowski (2009), que classificam "valores" como crenças expressas na excelência das ações, não estando apenas ligados a histórias individuais, mas inscritos nas histórias das sociedades. Desse modo, compreendemos que cada casal relaciona o conceito de valor à sua história individual e busca transmiti-los aos filhos, com base em ações distintas.

Embora sejam construções individuais e não haja a possibilidade de generalizar sua forma de transmissão, observamos nas narrativas dos pais que os valores estão relacionados com a crença de algo positivo, de cunho ético e amoroso como norteadores da vida, que se apreende pela convivência. 
No quadro 2, apresentamos a segunda categoria: "Quais valores são considerados importantes pelo casal", pois estamos diante de uma fase de vertiginosas mudanças, em que há "quebra de valores preexistentes" e ausência de novos valores relacionais, estáveis, estruturados e bem aceitos (Seixas, 2008). Portanto a complexidade do mundo atual nos expóe a uma vasta gama de influências que, em geral, dificultam a tomada de posiçôes claras a respeito de quais valores adotar e transmitir. Desse modo, compreendemos que a configuração da sociedade contemporânea exige que os pais façam reflexões e revisões constantes do que e como gostariam de transmitir a seus filhos, visto que também vivem situações distintas das que experimentaram quando tinham a idade destes.

Quadro 2. Valores considerados importantes

\begin{tabular}{|c|l|}
\hline $\mathbf{1}$ & $\begin{array}{l}\text { Respeito, amizade, amor, lealdade, sinceridade, } \\
\text { verdade, honestidade, cooperação, responsabilidade, } \\
\text { família, companheirismo, sensibilidade e confiança. }\end{array}$ \\
\hline $\mathbf{2}$ & $\begin{array}{l}\text { Responsabilidade, respeito, amor, amizade, } \\
\text { lealdade, cumplicidade, humildade, humanização, } \\
\text { confiança mútua, honestidade, persistência, família, } \\
\text { autoconfiança, disciplina e liberdade. }\end{array}$ \\
\hline $\mathbf{3}$ & $\begin{array}{l}\text { Integridade, humildade, honestidade, fé, família, } \\
\text { amor, carinho, dinheiro, companheirismo, amizade e } \\
\text { fraternidade. }\end{array}$ \\
\hline $\mathbf{4}$ & Religião, família, respeito, integridade e "ser do bem". \\
\hline
\end{tabular}

Fonte: elaborado pelos autores.

Os valores considerados mais importantes a serem transmitidos aos filhos e mencionados pela maioria dos pais e mães entrevistados foram: a família, o respeito, a amizade, o amor, a lealdade, a honestidade e o companheirismo.

Os pais associam esses valores a condutas familiares, a exemplos e atitudes praticados no dia a dia do convívio familiar. Também se referiram à responsabilidade, confiança, humildade, integridade e à fé. Valores esses compreendidos como positivos e desejáveis em nossa sociedade.

Observamos que a "família" é um valor comum a todos os casais, tendo em vista que essa instituição é de grande importância, o que faz com que os pais almejem que seus filhos aprendam a valorizá-la e a reconhecê-la como um lugar seguro ao qual sempre poderão recorrer, pois valores de lealdade, amizade, amor, fraternidade e companheirismo, que são por eles evidenciados, têm suas raízes no convívio familiar. Destacam-se, ainda, a honestidade e o respeito, além de outras variações que sugerem o mesmo tema.

Notamos também que os pais têm bastante clareza acerca do que gostariam de ensinar e transmitir aos filhos, elencando com grande propriedade os valores que consideram relevantes. Tal percepção é contrária às afirmações da literatura 
consultada sobre a falta de valores norteadores e quebra de valores preexistentes (Seixas, 2008). Diante disso, é necessário refletirmos sobre a possibilidade de os pais, na verdade, terem dificuldade em transmitir e ensinar valores em uma sociedade exposta à efemeridade, esboçando medo e preocupação em não realizar com sucesso a tarefa educativa que lhes compete, deixando de preparar seus filhos de maneira adequada para um futuro de incertezas, em constante construção.

Complementando nossa análise, a terceira categoria refere-se à "Percepção dos pais diante da tarefa de educar" (quadro 3); reafirmando a complexidade do fenômeno educacional os pais compreendem tal tarefa como uma atividade intensa e de extrema responsabilidade.

Quadro 3. Percepção da tarefa de educar

\begin{tabular}{|c|l|}
\hline $\mathbf{1}$ & $\begin{array}{l}\text { Tarefa de muita responsabilidade, dedicação, } \\
\text { planejamento e importância }\end{array}$ \\
\hline $\mathbf{2}$ & $\begin{array}{l}\text { Tarefa de muita responsabilidade, que se } \\
\text { transforma a partir da experiência e maturidade }\end{array}$ \\
\hline $\mathbf{3}$ & Tarefa difícil e de grande responsabilidade \\
\hline $\mathbf{4}$ & Tarefa difícil e que exige tempo e disponibilidade \\
\hline
\end{tabular}

Fonte: elaborado pelos autores.

Percebemos pelo discurso dos participantes que diante do afrouxamento das tradições, tornou-se constante para eles o confronto com a necessidade de escolhas. Tal processo permite a apropriação do universo social, no entanto traz muitas dúvidas e insegurança às práticas educativas parentais na atualidade, constituindo uma questão difícil para os casais o fato de fazer escolhas certas e responsáveis na educação dos filhos, tendo em vista que ficarão inscritas em sua identidade, sua vida individual, social e familiar.

Assim, conforme sugere Maldonado (2008), para os pais, educar consiste em assumir o compromisso de cuidar bem, de crescer junto com a criança, respeitando e acompanhando sua trajetória rumo à autonomia e à independência.

Ao concebermos a família como um sistema aberto e em constante transformação, como já dito anteriormente (Minuchin, 1982), compreendemos que, durante cada etapa do desenvolvimento dos filhos, é necessário que sejam adotadas novas e diversificadas estratégias para que o processo de educação e transmissão de valores tenha suas demandas atendidas e abarque as necessidades de cada etapa do ciclo vital, portanto, a quarta categoria, intitulada "Práticas educativas utilizadas pelo casal” (quadro 4), refere-se às estratégias adotadas pelo casal parental diante da transmissão de valores. 
Quadro 4. Práticas educativas utilizadas pelo casal

\begin{tabular}{|c|l|}
\hline $\mathbf{1}$ & $\begin{array}{l}\text { Diálogo, reflexão, cantinho do castigo, não } \\
\text { violência, consequência e responsabilização diante } \\
\text { dos atos, diferenciação de papéis, suporte e apoio } \\
\text { mútuo na relação conjugal. }\end{array}$ \\
\hline $\mathbf{2}$ & $\begin{array}{l}\text { Modelos, diálogo, não violência, diferenciação de } \\
\text { papéis, suporte e apoio mútuo na relação conjugal. }\end{array}$ \\
\hline $\mathbf{3}$ & $\begin{array}{l}\text { Castigo, não violência, religião, contato com a } \\
\text { realidade e diálogo. }\end{array}$ \\
\hline $\mathbf{4}$ & Modelos, diálogo e contato com a realidade. \\
\hline
\end{tabular}

Fonte: elaborado pelos autores.

As principais estratégias por eles utilizadas para transmitir esses valores referiam-se a conversar, promover reflexões, uso de não violência e o emprego de modelos e exemplos, além da responsabilização pelos seus atos e castigos não corporais.

Os casais também apontam para a importância do suporte mútuo na relação conjugal como sendo um elemento fortalecedor diante da relação com os filhos. Ademais, o suporte e apoio mútuo na relação conjugal tem sua importância reforçada ao retomarmos o conceito de subsistemas, os quais, aliados ao diálogo conjugal, auxiliam o casal na estruturação hierárquica, além de firmar a autoridade que, conforme explicitado anteriormente, é uma das grandes dificuldades da família contemporânea (Minuchin, 1982; Cerveny \& Berthoud, 2010).

A organização da família em subsistemas permite que o indivíduo se mantenha em seu processo de diferenciação, ao mesmo tempo em que abre espaço para o desenvolvimento e exercício de habilidades interpessoais em diferentes níveis.

Ao considerarmos a construção de significados pela linguagem na interação social, percebemos que as famílias adotam práticas interacionais embasadas no diálogo, promovendo, assim, a coconstrução dos valores norteadores dos princípios educacionais vigentes em cada sistema, reforçando a ideia de que os significados não são construídos individualmente, mas sim na interação que se dá entre os diferentes sistemas e subsistemas.

Observamos que três casais citam o não uso da violência, por acreditarem que a apresentação de modelos aos filhos é de extrema importância nesse processo, visto que concordam que há repetição de suas condutas nos ambientes sociais, o que reforça a concepção de que os valores se expressam na excelência das ações, conforme descrito por Macedo e Kublikowski (2009).

Por fim, na categoria referente aos "Desafios enfrentados pelos pais durante o processo educacional" (quadro 5), buscamos elencar as principais dificuldades vivenciadas durante a caminhada rumo à independência e autonomia das crianças. 
Quadro 5. Desafios enfrentados durante o processo de educação

\begin{tabular}{|c|l|}
\hline $\mathbf{1}$ & $\begin{array}{l}\text { Ser capaz de estabelecer limites sem desrespeitar } \\
\text { a identidade e o espaço da criança; não ser } \\
\text { autoritário; ensinar a ordem, a disciplina e educar } \\
\text { para a liberdade. Ensiná-los a se defender. }\end{array}$ \\
\hline $\mathbf{2}$ & $\begin{array}{l}\text { Admitir que seu filho é muito parecido com você; } \\
\text { prepará-lo para algo desconhecido; ensiná-lo a } \\
\text { valorizar as oportunidades, a se defender, adequar } \\
\text { o grau de exigência, conviver com nossas próprias } \\
\text { limitações, ansiedades e frustrações }\end{array}$ \\
\hline $\mathbf{3}$ & $\begin{array}{l}\text { Conseguir impedir que os filhos se envolvam } \\
\text { com coisas ruins, mostrar que, muitas vezes, o } \\
\text { que é chato é o que é certo, esperar que eles não } \\
\text { cometam os mesmos erros que nós. }\end{array}$ \\
\hline $\mathbf{4}$ & $\begin{array}{l}\text { Ser capaz de fazê-los tornarem-se pessoas de bem, } \\
\text { mas que saibam se defender. }\end{array}$ \\
\hline
\end{tabular}

Fonte: elaborado pelos autores.

Nessa categoria, deparamo-nos com a preocupação parental em preparar os filhos para algo desconhecido, referindo a defesa como uma importante estratégia a ser ensinada, contudo sem ferir a integridade física e desconsiderar o respeito pelo outro, como norte das ações individuais futuras.

Além disso, os pais e mães também referem a importância de fazer constantes autoavaliações e rever seus próprios conceitos sobre a vida, de modo que, com base em suas próprias experiências como filhos, possam construir novas possibilidades diante do novo papel e da função que agora ocupam.

Identificar semelhanças e reconhecer diferenças entre pais e filhos também é um desafio, dado que esse processo coloca cada cônjuge em contato com suas próprias ansiedades e frustrações diante daquilo que desejam para seus filhos.

Concordamos com Cerveny \& Berthoud (2010), ao pontuarem que a vivência da parentalidade é um período de tensão e de demandas que impulsionam o casal a promover mudanças, pois seus desejos e expectativas se confrontam com a realidade experienciada; valores e padrões adquiridos nas respectivas famílias de origem são revistos e renegociados com grande frequência, reiterando a necessidade de adaptações familiares constantes.

Por outro lado, o medo da perda dos filhos e do sofrimento gerado pelas fantasias de resultados negativos decorrentes, de uma educação marcada pelo fracasso talvez propicie um modo de cuidar permeado por certa dose de temor, cuja natureza faz com que os pais se lancem na antecipação das possibilidades do que pode acontecer com os filhos na vida. Portanto, afetados pelo peso da responsabilidade que sentem a respeito da educação dos filhos, temem acontecimentos que gerem danos (Santos \& Macedo, 2008). 
Consideramos que um dos grandes desafios da educação talvez seja transmitir os valores da cultura familiar e social no projeto de vida de cada um, assim como pontua o casal 1, que se preocupa com as repercussóes futuras que os valores transmitidos terão no futuro de seus filhos.

Ao concebermos que vivemos em um período de "ética da ambivalência", conforme pontuam Santos e Macedo (2008), deparamo-nos, por um lado, com a necessidade de educar os filhos para serem capazes de tomar decisões, bem como fazerem escolhas responsáveis, que não visem apenas a benefícios individuais; enquanto, por outro, somos levados a educá-los para a competitividade, a fim de prepará-los para o futuro, sem, contudo, ferir a conduta moral necessária para a vida em sociedade.

É comum nas narrativas de todos os casais a preocupação com a violência no ambiente escolar, o que gera questionamento sobre que conduta tomar para orientar os filhos a se defenderem das provocações e ofensas dos colegas, uma vez que se preocupam em não estimular a agressividade em seus filhos, ao mesmo tempo em que gostariam de que eles desenvolvessem a capacidade de se defender, se possível sem ultrapassar os limites da integridade física e moral do outro.

Compreendemos, pois, que o processo de educação se configura como algo que se constrói de maneira recíproca, em que pais e filhos aprendem diariamente, evoluindo como pessoas e desenvolvendo habilidades em seus papéis. A confiança de ambas as partes é de fundamental importância nessa relação, pois apenas assim as responsabilidades de ser pai, mãe e filhos serão assumidas mutuamente.

\section{CONSIDERAÇÕES FINAIS}

Baseados na concepção de que a infância representa a fase inicial do processo de formação e socialização do indivíduo, debruçamo-nos sobre a percepção dos familiares em relação aos valores a serem transmitidos a seus filhos, bem como no processo dessa transmissão.

Há algumas décadas, a tarefa de criar filhos era algo inquestionável e se baseava em costumes e tradições bem estabelecidas, mas dada a complexidade do mundo atual, sobretudo a queda das fronteiras entre as culturas pelos meios de comunicação e pela globalização, não se tem mais parâmetros precisos que guiem esse processo, cabendo aos pais fazerem escolhas responsáveis diante dessa árdua tarefa. No entanto tais escolhas não têm como prever a concretização de desejos ou planos, visto que, a partir dos processos de mudança e da efemeridade das práticas sociais, não se sabe o que o futuro reserva aos pequenos, em termos de aplicabilidade dos valores transmitidos na família. 
Percebemos que educar filhos é um processo particular de cada família, o qual exige cuidado, compreensão, criatividade, responsabilidade e ética, pois seus reflexos contribuirão para a transformação tanto de pais quanto de filhos no decorrer dessa experiência.

Além disso, durante o processo de educação, os pais revivem, por um novo olhar (mais maduro e experiente) as próprias dificuldades enquanto filhos, o que significa que terão a necessidade de ressignificar alguns de seus conceitos para que sejam capazes de mostrar aos descendentes o que consideram relevante, por meio de exemplos e diálogo construtivo, sem a imposição de modos de agir e pensar. Cada nova etapa do desenvolvimento dos filhos exige dos pais uma nova habilidade, representando um desafio à sua flexibilidade e capacidade de adaptação.

Educar é uma tarefa árdua, como eles próprios reconhecem, diante da qual, na maioria das vezes, dispomos apenas de nossas experiências de vida, intuição e da predisposição para amar e fazer o melhor para os filhos, como únicas bagagens. Dessa forma, o processo de educação representa amadurecimento, aprendizado e crescimento mútuos por meio de uma relação alicerçada na confiança.

Quando recorremos à nossa capacidade de amor, proteção e afeto, nossas relações tendem a ser cada vez mais igualitárias, com autoridade sem autoritarismo, tornando a relação mais horizontalizada, sendo necessário desenvolvermos habilidades voltadas para o diálogo, pelo qual podemos negociar, argumentar e coconstruir soluções que, de uma maneira geral, criam um contexto favorável ao processo educativo. Assim, é necessário que pais e filhos sejam capazes de dialogar para que a comunicação seja mais efetiva, incorporando essa prática como mais um valor ao convívio familiar.

Acreditamos que os objetivos propostos a esse trabalho foram atingidos visto que, com base nas narrativas parentais, foi possível ter acesso a suas percepções sobre a tarefa de educar, bem como à concepção de valores e quais consideram importantes transmitir. Acredita-se que a complexidade do tema, por sua natureza resultante da interação de costumes, tradições e mudanças socioculturais, explique em boa medida o forte acento no amor, respeito, confiança colocado pelos pais, como meio de assegurar uma relação que facilite sua tarefa educativa, tornando difícil uma análise mais detalhada dos valores considerados mais importantes.

Fica claro que os pais assumem que a família representa o alicerce para a transmissão intergeracional de valores.

Todavia é válido ressaltar as limitações de nosso estudo, visto que contou com uma amostra restrita em que grande parte dos entrevistados mostrava-se afinado 
e preocupado com a responsabilidade da educação dos filhos, além dos valores fundamentais associados aos processos de transmissão intergeracional.

De fato, o tema da educação de filhos implica incontáveis aspectos, tornando difícil abarcá-lo em sua totalidade, dada sua natureza complexa, o que reforça a necessidade de mais estudos enfocando a temática das relações familiares e sua importância na cadeia de transmissão de valores na criação de filhos na Contemporaneidade. A escassez de estudos sobre essa temática também reforça a necessidade de novas pesquisas e metodologias voltadas para a compreensão dos processos educativos de formação nas famílias.

Finalizamos nossas reflexões destacando que educar é, sobretudo, uma arte que se configura com base na expressão de atos de amor, respeito e confiança, que envolvem ensinar a criança a desenvolver julgamento moral, refletir sobre seus próprios erros, aprender com eles, adquirir consciência ética, a saber conviver em harmonia, a saber agir e pensar com responsabilidade e liberdade. Enfim, é desenvolver habilidades sociais e ensinar cidadania calcada em valores positivos, visando a possibilitar aos filhos atuação ética de acordo com os princípios morais da sociedade em que se vive. 


\section{REFERÊNCIAS}

Cacciacarro, M. F. (2013). A arte de educar: a tarefa de transmitir valores sob a perspectiva parental. (Monografia), Pontifícia Universidade Católica, Coordenadoria Geral de Especialização, São Paulo.

Cerveny, C. M. D. O. \& Kublikowski, I. (1998). O eu e o elo: a história de uma herança. Revista da Associação Brasileira de Psicoterapia Analítica de Grupo, 7, $7-15$.

Cerveny, C. M. O. \& Berthoud, C. M. E. (2010). Visitando a familia ao longo do ciclo vital. (3a ed.). São Paulo: Casa do Psicólogo.

Creswell, J. W. (2009). Research design: qualitative, quantitative and mixed methods aproaches. (3rd ed.). Los Angeles: Sage Publications.

Cunha, G., Guimarães, E. S. C., \& Mourão, R. (2008). Resgatar a autoridade parental: educar pais e filhos. In R. M. S. Macedo (Org.), Terapia familiar no Brasil na última década. (pp. 142-156). São Paulo: Rocca.

Gomide, P. I. C. (2011). Pais presentes, pais ausente: regras e limites. (10a ed.). Petrópolis: Vozes.

Grandesso, M. (2011). Sobre a reconstrução do significado. São Paulo: Casa do Psicólogo.

Guba, E. G. \& Lincoln, Y. S. (1994). Competing paradigms in qualitative research. In N. K. Denzin \& Y. S. Lincoln (Eds.), Handbook of qualitative research. London: Sage Publications.

Kobarg, A. P. R., Sachetti, V. A. R., \& Vieira, M. L. (2006). Valores e crenças parentais: reflexões teóricas. Revista Brasileira de Crescimento e Desenvolvimento Humano, 16(2), 96-102.

Lombardia, P. G. (2008). Quem é a geração Y? HSM Management, 70, 1-7.

Macarini, S. M., Martins, G. D. F., Minetto, M. F. J., \& Vieira, M. L. (2010). Práticas parentais: uma revisão da literatura brasileira. Arquivos Brasileiros de Psicologia, 62(1), 119-134.

Macedo, R. (2008). Pesquisa qualitativa com famílias e casais. In I. C. Z. Guerreiro; M. L. S. Schimidt \& F. Zucker (Orgs.), Ética nas pesquisas em Ciências Humanas, Sociais e na Saúde. (pp. 167-177). São Paulo: Aderaldo e Rothschild. 
Macedo, R. M. S \& Kublikowski, I. (2009). Valores positivos e desenvolvimento do adolescente: perfil de jovens paulistanos. Psicologia em Estudo, 14(4), 689698.

Macedo, R. M. S., Kublikowski, I., \& Berthoud, C. M. E. (2006). Valores positivos e desenvolvimento do adolescente: a perspectiva dos pais. Revista Brasileira de Crescimento e Desenvolvimento Humano, 16(2), 38-52.

Macedo, R. M. S, Kublikowski, I., \& Grandesso, M. (2004). A interpretação em pesquisa qualitativa: a construção do significado. In Anais, 1 Conferência Internacional do Brasil de Pesquisa Qualitativa. (p. 83). Taubaté: Núcleo de Pesquisa da Família.

Maldonado, M. T. (2008). Comunicação entre pais e filhos. São Paulo: Integrare.

Martins Filho, J. (2012). A criança terceirizada: os descaminhos das relaçôes familiares no mundo contemporâneo. (6a ed.). Campinas: Papirus.

Minuchin, S. (1982). Famílias, funcionamento e tratamento. Porto Alegre: Artes Médicas.

Morici, A.C. (2008). Pós-modernidade: novos conflitos e novos arranjos familiares. In R. M. S. Macedo (Org.), Terapia familiar no Brasil na última década. (pp. 64-71). São Paulo: Rocca.

Morin, E. (2005). Ciência com consciência. (9a ed.) Rev. mod. pelo autor. M. D. Alexandre \& M. A. S. Déria, (Trad.). Rio de Janeiro: Bertrand Brasil.

Resolução no 466, de 12 de dezembro (2012, 12 dezembro). O Plenário do Conselho Nacional de Saúde em sua 240a Reunião Ordinária, realizada nos dias 11 e 12 de dezembro de 2012, no uso de suas competências regimentais e atribuições conferidas pela Lei $\mathrm{n}^{\circ}$ 8.080, de 19 de setembro de 1990, [...]. Diário Oficial da União, Brasília, no 466, de 12 dez. 2012. Recuperado a partir de http://bvsms.saude.gov.br/bvs/saudelegis/cns/2013/res0466_12_12_2012. html

Santos, J. L. (2006). “Transformando"- "nós” em "laços": um estudo compreensivo dos valores parentais nas práticas educativas em famílias de baixa renda. (Dissertação de Mestrado). Pontifícia Universidade Católica de São Paulo, Programa de Pós-Graduação em Psicologia, São Paulo. 
Santos, J. L. (2011). Casa de pais, escola de filhos: um estudo sobre as transformaçōes nos significados, valores e práticas de educar filhos em famílias de baixa renda. (Tese de Doutorado), Pontifícia Universidade Católica de São Paulo, Programa de Pós-Graduação em Psicologia, São Paulo.

Santos, J. L. \& Macedo, R. M. S. (2008). Valores familiares e educação dos filhos na Contemporaneidade. In R. M. S. Macedo (Org.), Terapia familiar no Brasil na última década. (pp. 169-179). São Paulo: Rocca.

Seixas, M. R. A. (2008). Compete ao terapeuta de família trabalhar valores? In R. M. S. Macedo (Org.), Terapia familiar no Brasil na última década. (pp. 1726). São Paulo: Rocca.

Vasconcellos, M. J. E. de (2003). Pensamento sistêmico: o novo paradigma da ciência. Campinas: Papirus. 